ПРОЛАКТОЛИБЕРИН УВЕЛИЧИВАЕТ ТРЕВОЖНОСТЬ КРЫС

( Д.А. Жуков ${ }^{1 *}$, А.Г. Марков², Е.П. Виноградова ${ }^{2}$

'Институт физиологии им. И.П. Павлова РАН, Санкт-Петербург, Россия

${ }^{2}$ Биологический факультет СПбГУ, Санкт-Петербург, Россия

ОБОСНОВАНИЕ. Пролактолиберин, или пролактин-рилизинг-гормон (Прл-РГ), помимо стимуляции выработки пролактина, взаимодействует с различными отделами ЦНС, участвуя в реализации многих функций, отражающихся в поведении.

ЦЕЛЬ. Поскольку в литературе нет данных о связи Прл-РГ с тревожностью, целью данной работы явилось изучение влияния Прл-РГ на тревожность белых крыс Вистар.

МАТЕРИАЛЫ И МЕТОДЫ. Тревожность оценивали в двух тестах. В приподнятом крестообразном лабиринте регистрировали время, проводимое в открытых рукавах и количество реакций свешивания, В тесте социального предпочтения регистрировали время, проводимое возле чужака, возле знакомой особи и на нейтральной территории.

РЕЗУЛЬТАТЫ. Введение Прл-РГ в дозе 10-10 М объемом 10 мкл в каждую ноздрю уменьшало время, проводимое животными в открытых рукавах приподнятого крестообразного лабиринта, и количество реакций свешивания. Для тестирования социального взаимодействия животных предварительно отбирали по высокому либо низкому уровням тревожности в тесте с приподнятым крестообразным лабиринтом. У крыс с изначально низким уровнем тревожности Прл-РГ уменьшал время, проводимое рядом с незнакомцем, что указывает на повышение уровня тревожности. Поведение крыс с изначально высоким уровнем тревоги не менялось после введения Прл-РГ.

ЗАКЛЮЧЕНИЕ. Результаты наших экспериментов свидетельствуют о том, что интраназальное введение Прл-РГ увеличивает тревожность крыс.

КЛЮЧЕВЫЕ СЛОВА: пролактолиберин; интраназальное введение; тревожность; сочиальное предпочтение; крыса.

\title{
PROLACTIN-RELEASING PEPTIDE INCREASES RAT ANXIETY
}

(c) Dmitry A. Zhukov*, Alexandr G. Markov², Ekaterina P. Vinogradova²

'Pavlov Institute of Physiology RAS, St-Petersburg, Russia

${ }^{2}$ Biological Faculty, SPb State University, St-Petersburg, Russia

BACKGROUND: Prolactin-releasing peptide(Prl-RP), in addition to stimulating the production of prolactin, interacts with various parts of the central nervous system, participating in the implementation of many functions that are reflected in behavior.

AIM: The effect of Prl-RP on the anxiety of white Wistar rats was studied since there were no data in the literature on the relationship between Prl-RP and anxiety.

MATERIALS AND METHODS: Anxiety was assessed in two tests. In the elevated plus-maze (EPM), the time spent in the open arms and the number of edge reactions were recorded. In the social preference test, the time spent near a stranger, near a familiar individual, and in neutral territory were recorded.

RESULTS: The administration of Prl-RP at a dose of 10-10 M with a volume of $10 \mu$ in each nostril reduced the time spent by the animals in the open arms of the EPM, and the number of edge reactions. For testing the social interaction, animals were pre-selected for high or low levels of anxiety in the EPM. In rats with initially low levels of anxiety, Prl-RP reduced the time spent near a stranger, indicating an increase in anxiety levels. The behavior of rats with initially high levels of anxiety did not change after application of the Prl-RP.

CONCLUSION: The results of our experiments indicate that the intranasal administration of Prl-RP increases the anxiety of rats.

KEYWORDS: prolactin-releasing peptide; intranasal administration; anxiety; social preference; rat. 


\section{ОБОСНОВАНИЕ}

Пролактолиберин (Прл-РГ) - гипоталамический нейрогормон, выделенный из экстракта гипоталамуса крупного рогатого скота [1, 2], увеличивал синтез пролактина в клеточной линии, полученной от аденомы гипофиза крыс, и в клетках гипофиза лактирующих крыс [3]. Кроме того, инъекция Прл-РГ стимулировала уровень пролактина в плазме крови у самок крыс в проэструсе, эструсе и метаэструсе и дозозависимым образом повышала уровень пролактина в плазме крови у самцов крыс [4].

Ранее исследований связи Прл-РГ и тревожности не проводилось. Для большинства изученных нейропептидов в настоящее время показано наличие не только физиологических, но и психотропных эффектов. Но если психотропные эффекты кортиколиберина, гонадолиберина, окситоцина, вазопрессина и т.д. активно исследуются, то влияние пролактолиберина на поведение и психику в настоящее время изучено слабо - Прл-РГ считается анорексигенным (снижающим потребление пищи) нейропептидом, который в основном играет роль В регуляции потребления пищи и расхода энергии [5]. Производные Прл-РГ обладают широким терапевтическим потенциалом [6], поскольку Прл-РГ проявляет не только анорексигенные, но и нейропротекторные свойства [7] и участвует в стрессорной реакции [8].

Для врачей эти данные могут представлять интерес, поскольку медицинские препараты, как правило, имеют побочные эффекты. Часто эти эффекты связаны с изменением эмоционального фона. Именно потому, что Прл-РГ и его синтетические аналоги обладают терапевтическим потенциалом, важно учитывать возможное влияние ПрлРГ на эмоциональную сферу, изучению чего и посвящена данная работа.

\section{ЦЕЛЬ ИССЛЕДОВАНИЯ}

В данной работе мы исследовали влияние интраназального введения крысам Прл-РГ на тревожность обязательный компонент стрессорной реакции организма и на реакцию социального предпочтения.

\section{МАТЕРИАЛЫ И МЕТОДЫ}

Опыты проводили на 116 самцах крыс Вистар со средней массой 160 г в возрасте 2 мес на момент начала эксперимента в трех независимых сериях. Животных содержали в стандартных условиях при свободном доступе к пище (сухой комбикорм для грызунов) и воде, по 5 особей в клетке. Перед началом эксперимента животных в течение 14 дней ежедневно по 5 мин подвергали процедуре хэндлинга для предотвращения стрессорной реакции на взятие в руки в период проведения экспериментов [9].

Для оценки тревожности животных тестировали во всех сериях экспериментов в приподнятом крестообразном лабиринте (ПКЛ). Тревожность, определяемая по данной методике, отражает естественный страх высоты и открытых пространств у грызунов. Уровень тревожности определяется обратно пропорционально времени, проводимому в открытых рукавах.

Время тестирования составляло 5 мин. После тестирования каждой крысы лабиринт протирали раствором перекиси водорода для уничтожения запаха предыдущего животного. Тестирование проводили с 13 до 17 ч.

На первом этапе эксперимента в трех сериях изучали влияние Прл-РГ на уровень тревожности белых крыс в тесте ПКЛ с использованием различных концентраций.

Животным группы контроля $(\mathrm{n}=42)$ за 15 мин до теста ПКЛ вводили физиологический раствор $(0,9 \% \mathrm{NaCl})$ по 10 мкл в каждую ноздрю. Животным из опытной группы интраназально вводили Прл-РГ (Prolactin-releasing Peptide, Hybio Pharmaceuticals) объемом по 10 мкл в каждую ноздрю (20 мкл на крысу) в дозе $10^{-10}$ моль/л ( $\left.\mathrm{n}=29\right)$ и в дозе $10^{-11}$ моль/л $(\mathrm{n}=14)$ за 15 мин до теста.

Во второй серии экспериментов $(\mathrm{n}=31)$, через неделю после тестирования в ПКЛ, поведение животных исследовали в тесте «социальное предпочтение».

На ограниченном стенками (высота 35 см) квадратном поле $(90 \times 90 \times 70$ см) в противоположных углах размещали маленькие клетки, в которых помещали крыс. Клетки были изготовлены из пластмассовых решеток (18×18×18 см), что обеспечивало в ходе эксперимента визуальный, обонятельный и тактильный контакты между животными, но предотвращало агонистические взаимодействия. Подробнее методика описана ранее (Виноградова и др., 2009) [9].

Исследуемых животных делили на две группы. Первой группе (опыт) вводили Прл-РГ по 10 мкл в концентрации $10^{-10}$ М в каждую ноздрю (20 мкл на крысу) за 15 мин до теста. Второй группе, контрольным животным, вводили $0,9 \% \mathrm{NaCl}$ (20 мкл на крысу). В одну клетку помещали крысу-чужака - животное, которое ранее ни разу не имело никаких социальных контактов с исследуемым животным, в другую - крысу из той же жилой клетки, что и тестируемое животное. Исследование проводили в светлое время суток с 13 до 16 ч, длительность теста 5 мин. Тестируемое животное помещали в центр поля. Учитывалось время нахождения крысы на площади рядом с каждой из клеток (10\% от общей свободной площади) и на нейтральном пространстве (80\%). Все эксперименты снимались на видеокамеру.

Видеозапись поведения животных проводили на вебкамеру Logitech Webcam (Switzerland).

Статистическая обработка проводилась с использованием непараметрических методов статистики: критерия U Манна-Уитни в программе SPSS-17. За уровень статистической значимости принято значение $p<0,05$.

\section{ЭТИЧЕСКАЯ ЭКСПЕРТИЗА}

Исследование было проведено в соответствии с правилами, принятыми Европейской конвенцией по защите позвоночных животных (Страсбург, 1986) [10]; Приказом МЗ РФ №119 Н от 1 апреля 2016 г. «Об утверждении Правил лабораторной практики», Principles of Good Laboratory Practice (OECD, ENV/MC/CUEM (98) 17, 1997); ГОСТ 33044-2014 «Принципы надлежащей лабораторной практики» (идентичен GLP OECD); со статьей 11 Федерального закона от 12 апреля 2010 г. №61-Ф3 «Об обращении лекарственных средств» (ред. от 22.10.14). Были предприняты надлежащие меры по соблюдению биоэтических норм сокращения количества исследуемых животных. На проведение экспериментов было получено разрешение этического комитета в области исследований на животных Санкт-Петербургского государственного университета. 
Таблица 1. Показатели поведения в приподнятом крестообразном лабиринте

\begin{tabular}{|c|c|c|c|c|}
\hline & $\begin{array}{c}\text { Контроль } \\
\mathrm{NaCl} \\
(\mathbf{n}=\mathbf{2 8})\end{array}$ & $\begin{array}{c}\text { Пролактолиберин } \\
10^{-10} \mathrm{M} \\
\mathrm{n}=29\end{array}$ & $\begin{array}{c}\text { Контроль } \\
\mathrm{NaCl} \\
\mathrm{n}=14\end{array}$ & $\begin{array}{c}\text { Пролактолиберин } \\
10^{-11} \mathrm{M} \\
\mathrm{n}=14\end{array}$ \\
\hline Время в открытых рукавах, с & $48,7 \pm 7,4$ & $28,2 \pm 6,2^{*}$ & $45 \pm 5,2$ & $43 \pm 6,3 \#$ \\
\hline Количество свешиваний & $4,5 \pm 0,9$ & $1,9 \pm 0,2^{*}$ & $5,8 \pm 1,1$ & $6,3 \pm 1,2 \#$ \\
\hline Количество стоек & $6,8 \pm 0,9$ & $6,1 \pm 1,1$ & $7,1 \pm 1,1$ & $7,2 \pm 1,1$ \\
\hline Двигательная активность, см & $282 \pm 21,2$ & $253 \pm 28,3$ & $272 \pm 22,8$ & $261 \pm 30,2$ \\
\hline Акты груминга & $2,8 \pm 0,5$ & $3,5 \pm 0,4$ & $3,2 \pm 0,9$ & $5,8 \pm 1,2$ \\
\hline
\end{tabular}

Примечание. * - p<0,05, сравнение показателей между группами «опыт» и «контроль»; \# - p<0,05, сравнение показателей животных между группами «опыт 1» (концентрация $\left.10^{-10} \mathrm{M}\right)$ и «опыт 2» (10-11 M) (критерий Манна-Уитни).

\section{РЕЗУЛЬТАТЬ}

Введение Прл-РГ в концентрации 10-10 ммоль приводило к тому, что крысы проводили меньше времени в открытых рукавах лабиринта, демонстрировали меньшее количество свешиваний и заходов в открытые рукава, чем животные контрольной группы, что свидетельствует о более высоком уровне тревожности у них (табл. 1). Достоверных различий по двигательной активности, количеству стоек, частоте и длительности груминга между отдельными группами не выявлено. Введение Прл-РГ в концентрации 10-11 ммоль не оказывало влияния ни на один из оцениваемых параметров поведения В ПКЛ.

В тесте социального предпочтения средние значения времени, проведенного со «своим» или «чужим»у животных, которым вводили Прл-РГ, достоверно не отличались от данных, полученных в группе контроля (табл. 2). Однако оказалось, что эффект Прл-РГ зависит от исходного уровня тревожности, который был определен в первой серии экспериментов (см. табл. 1). Если выделить две группы животных - низко- и высокотревожных, их реакция на Прл-РГ различна.

После введения Прл-РГ в концентрации 10-10 ммоль крысы с исходно высоким уровнем тревожности (сред-

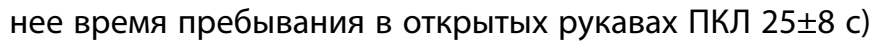

не демонстрировали достоверно значимого предпочтения к знакомому или незнакомому животному, т.е. у высокотревожных особей введение Прл-РГ не влияло на предпочтение «знакомца» или «незнакомца» (табл. 3).

Низкотревожные крысы (среднее время пребывания в открытых рукавах ПКЛ 146 21 с) проводили больше времени рядом с незнакомой особью, чем со знакомой. Эти данные совпадают с ранее полученными результатами (Виноградова, Лукина, Жуков, 2009) [9].

После введения Прл-РГ низкотревожные животные меньше времени проводили с чужаком, чем животные из контрольной группы (см. табл. 3), т.е. они демонстрировали предпочтение поведения, сходного с поведением высокотревожных животных группы «контроль».

\section{ОБСУЖДЕНИЕ}

Наиболее важным результатом данного исследования является то, что интраназальное введение Прл-РГ в наномолярной концентрации приводит к увеличению уровня тревожности, но не оказывает влияния на двигательную активность у крыс. Это указывает на анксиогенный, а не седативный эффект Прл-РГ.

Вероятно, влияние введения Прл-РГ на социальное предпочтение связано именно с изменением уровня тревоги.

Таблица 2. Социальное предпочтение в тесте «свой-чужой». Среднее время, проводимое крысами на разных участках экспериментальной камеры

\section{Время, проводимое со «своим», С}

\section{Время, проводимое \\ с «чужим», c}

Время, проводимое
на нейтральной
территории, с
$78,5 \pm 11,0$
$100,6 \pm 14$

\begin{tabular}{|c|c|c|c|}
\hline Контроль (n=15) & $77,9 \pm 20,6$ & $143,3 \pm 29,7$ & $78,5 \pm 11,0$ \\
\hline Прл-РГ $10^{-10}$ M (n=16) & $117 \pm 20,7$ & $83,3 \pm 23,3$ & $100,6 \pm 14$ \\
\hline
\end{tabular}

Таблица 3. Социальное предпочтение низко- и высокотревожных крыс в тесте «свой-чужой». Среднее время, проводимое крысами на разных участках экспериментальной камеры.

\begin{tabular}{lcccccc}
\hline & \multicolumn{3}{c}{ Высокотревожные $(\mathbf{n = 1 2 )}$} & \multicolumn{3}{c}{ Низкотревожные (n=13) } \\
\cline { 2 - 7 } & свой & чужой & нейтр. & свой & чужой & нейтр. \\
\hline Контроль & $110 \pm 32$ & $100 \pm 28,8$ & $90 \pm 27$ & $84 \pm 18$ & $167 \pm 26.7 \#$ & $49 \pm 7,7$ \\
Про-РГ 10-10 M & $104 \pm 27$ & $89 \pm 39$ & $107 \pm 24$ & $131 \pm 35$ & $78 \pm 27,0 *$ & $91 \pm 21$ \\
\hline
\end{tabular}

Примечание. * - p<0,05, сравнение показателей между группами «опыт» и «контроль»; \# - р<0,05, сравнение показателей между временем, проводимым рядом со своим и чужим (критерий Манна-Уитни). 
В контроле животные с врожденной низкой тревожностью предпочитали общество незнакомца, а животные с врожденной высокой тревожностью, наоборот, - знакомой особи [9]. Это различие связано, вероятно, с балансом мотиваций. В новой обстановке у крысы происходит столкновение двух мотиваций: самосохранения и исследовательской. Можно предположить, что у крыс с высокой базальной тревожностью мотивация самосохранения сильнее исследовательской мотивации, поэтому они предпочитают находиться рядом с животным из своей клетки. У крыс с низким уровнем тревожности менее выражена неофобия, и они на этом фоне могут позволить себе проявить интерес к незнакомому животному, т. е. исследовательскую активность.

Центральные механизмы психотропных эффектов Прл-РГ изучены слабо, но показана возможность взаимодействия Прл-РГ со структурами ЦНС, регулирующими эмоции и стрессорный ответ $[6,11]$. Клеточные тела, окруженные иммунореактивной меткой, обнаружены, помимо гипоталамуса, в ядре одиночного тракта и вентромедиальном продолговатом мозге [12]. Метка в нервных проекциях присутствует в гипоталамусе, а также и в таламических ядрах, в миндалине и в конечной пластинке продолговатого мозга [12]. мРНК Прл-РГ экспрессируется в ядре одиночного тракта ствола мозга в несколько меньшей степени - в дорзомедиальном ядре гипоталамуса и в вентролатеральном ретикулярном ядре таламуса $[12,13]$.

Рецептор, обладающий высоким сродством к ПрлPГ, назван GPR10 (связанный с G-белком 10) [2]. мPHK GPR10 экспрессируется в нескольких отделах мозга крысы, в первую очередь в таламусе, гипоталамусе и в area postrema $[12,14]$. Рецептор GPR10 найден и в парабрахиальном ядре, и в прилежащем ядре [1], структурах ноцицептивной системы, а также в гиппокампе [15], участвующем в реализации многочисленных функций, в том числе и стрессорного ответа организма.

Несомненно участие Прл-РГ в стрессорной реакции $[8,16]$. Нейроны срединного возвышения, продуцирующие Прл-РГ, активируются при электро-болевом раздражении [17]. Мыши с нокаутным геном Прл-РГ реагируют на иммобилизационный стресс иначе, чем контрольные животные: у нокаутов повышено содержание глюкозы и кортикостерона в крови [18]. Прл-РГ-ергические нейроны ядра одиночного тракта активируются стрессорными стимулами [19]. Внутрижелудочковое введение Прл-РГ увеличивает концентрацию кортикостерона и окситоцина в крови, а введение антисыворотки Прл-РГ препятствует стрессорной активации паравентрикулярного ядра гипоталамуса и уменьшает выделение окситоцина в кровь [20].

\section{ЗАКЛЮЧЕНИЕ}

Подводя итог, наше исследование впервые показало, что Прл-РГ участвует и в эмоциональном компоненте стрессорной реакции: интраназальное введение Прл-РГ увеличивает тревожность крыс, что проявляется в избегании открытых рукавов ПКЛ и в снижении интереса к незнакомым особям в тесте социального предпочтения. Механизмы этих эффектов, а также возможная роль Прл-РГ в формировании тревожных и депрессивных расстройств требуют дальнейшего изучения, но уже сейчас очевидны возможности создания новых противотревожных препаратов на основе производных Прл-РГ.

\section{ДОПОЛНИТЕЛЬНАЯ ИНФОРМАЦИЯ}

Источники финансирования. Плановая НИР Института физиологии им. И.П. Павлова РАН по теме 63.1.

Конфликт интересов. Авторы декларируют отсутствие явных и потенциальных конфликтов интересов, связанных с содержанием настоящей статьи.

Участие авторов. Все авторы одобрили финальную версию статьи перед публикацией, выразили согласие нести ответственность за все аспекты работы, подразумевающую надлежащее изучение и решение вопросов, связанных с точностью или добросовестностью любой части работы.

Благодарности. Мы благодарим П.В. Волчека за техническую помощь.

\section{СПИСОК ЛИТЕРАТУРЫ | REFERENCES}

1. Welch SK, O'Hara BF, Kildu TS, Heller HC. Sequence and tissue distribution of a candidate G-coupled receptor cloned from rat hypothalamus. Biochem. Biophys. Res. Commun. 1995;209(2):606-613. doi: https://doi.org/10.1006/bbrc.1995.1543

2. Dodd GT, Luckman SM. Physiological Roles of GPR10 and PrRP Signaling. Front Endocrinol (Lausanne). 2013;4:20. doi: https://doi.org/10.3389/fendo.2013.00020

3. Hinuma S, Habata Y, Fujii R, et al. A prolactin-releasing peptide in the brain. Nature. 1998;393(6682):272-276. doi: https://doi. org/10.1038/30515. Erratum in: Nature. 1998;394(6690):302.

4. Matsumoto H, Noguchi J, Horikoshi Y, et al. Stimulation of prolactin release by prolactin-releasing peptide in rats. Biochem Biophys Res Commun. 1999;259(2):321-324. doi: https://doi.org/10.1006/bbrc.1999.0789

5. Takayanagi Y, Matsumoto H, Nakata M, et al. Endogenous prolactinreleasing peptide regulates food intake in rodents. $J$ Clin Invest. 2008;118(12):4014-4024. doi: https://doi.org/10.1172/JCI34682. Erratum in: J Clin Invest. 2009;1 19(2):422.

6. Pražienková V, Popelová A, Kuneš J, Maletínská L. Prolactin-releasing peptide: Physiological and pharmacological properties. Int. J. Mol. Sci. 2019;20:5297. doi: https://doi.org/10.3390/ijms20215297
7. Holubová M, Hrubá L, Popelová A, et al. Liraglutide and a lipidized analog of prolactin-releasing peptide show neuroprotective effects in a mouse model of $\beta$-amyloid pathology. Neuropharmacology. 2019;144:377-387. doi: https://doi.org/10.1016/j.neuropharm.2018.11.002

8. Maniscalco JW, Rinaman L. Interoceptive modulation of neuroendocrine, emotional, and hypophagic responses to stress. Physiol Behav. 2017;176:195-206. doi: https://doi.org/10.1016/j.physbeh.2017.01.027

9. Виноградова Е.П., Жуков Д.А., Лукина Е.А. Социальные предпочтения у белых крыс с высоким и низким уровнем тревожности // Журнал высшей нервной деятельности. 2010. — T. 60. — №1. - C. 39-45. [Vinogradova EP, Lukina EA, Zhukov DA. Social preference of white rats with high and low anxiety. Zh Vyssh Nerv Deiat. 2010;60(1):74-79. (In Russ.)].

10. European Convention for the Protection of Vertebrate Animals Used for Experimental and other Scientific Purposes. European Trety Series. 1986;123:1-11. Available from: https://rm.coe.int/168007a67b

11. Norris DO, Carr JA. Organization of the mammalian hypothalamuspituitary axes. In: DO Norris, JA Carr, editors. Vertebrate Endocrinology (Sixth Edition), Academic Press; 2021. P. 91-150. doi: https://doi.org/10.1016/B978-0-12-820093-3.00004-6. 
12. Roland BL, Sutton SW, Wilson SJ, et al. Anatomical distribution of prolactin-releasing peptide and its receptor suggests additional functions in the central nervous system and periphery. Endocrinology. 1999;140(12):5736-5745. doi: https://doi.org/10.1210/endo.140.12.7211

13. Morales T, Hinuma S, Sawchenko PE. Prolactin-releasing peptide is expressed in afferents to the endocrine hypothalamus, but not in neurosecretory neurones. J Neuroendocrinol. 2000;12(2):131-140. doi: https://doi.org/10.1046/j.1365-2826.2000.00428.x

14. Ibata Y, lijima N, Kataoka Y, et al. Morphological survey of prolactinreleasing peptide and its receptor with special reference to their functional roles in the brain. Neurosci Res. 2000;38(3):223-230. doi: https://doi.org/10.1016/s0168-0102(00)00182-6

15. Špolcová A, Mikulášková B, Holubová M, et al. Anorexigenic lipopeptides ameliorate central insulin signaling and attenuate tau phosphorylation in hippocampi of mice with monosodium glutamate-induced obesity. J Alzheimers Dis. 2015;45(3):823-835. doi: https://doi.org/10.3233/JAD-143150

16. Maniscalco JW, Rinaman L. Interoceptive modulation of neuroendocrine, emotional, and hypophagic responses to stress. Physiol Behav. 2017;176:195-206 doi: https://doi.org/10.1016/j.physbeh.2017.01.027

17. Morales T, Sawchenko PE. Brainstem prolactinreleasing peptide neurons are sensitive to stress and lactation. Neuroscience. 2003;121(3):771-778. doi: https://doi.org/10.1016/s0306-4522(03)00522-0

18. Mochiduki A, Takeda T, Kaga S, Inoue K. Stress response of prolactin-releasing peptide knockout mice as to glucocorticoid secretion. J Neuroendocrinol. 2010;22(6):576-584. doi: https://doi.org/10.1111/j.1365-2826.2010.01993.x

19. Card JP, Johnson AL, Llewellyn-Smith IJ, et al. GLP-1 neurons form a local synaptic circuit within the rodent nucleus of the solitary tract. J Comp Neurol. 2018;526(14):2149-2164. doi: https://doi.org/10.1002/cne.24482

20. Zhu LL, Onaka T. Facilitative role of prolactin-releasing peptide neurons in oxytocin cell activation after conditionedfear stimuli. Neuroscience. 2003;118(4):1045-1053. doi: https://doi.org/10.1016/s0306-4522(03)00059-9

Рукопись получена: 17.06.2021. Одобрена к публикации: 09.09.2021. Опубликована online: 30.10.2021.

\section{ИНФОРМАЦИЯ ОБ АВТОРАХ [AUTHORS INFO]}

*Жуков Дмитрий Анатольевич, д.б.н., доцент [Dmitry A. Zhukov, PhD]; адрес: Россия, 199034, Санкт-Петербург, наб. Макарова, д. 6 [address: 6 Makarova, 199034, St-Petersburg, Russia]; ORCID: http://orcid.org/0000-0002-5716-0027; eLibrary SPIN: 1416-0551; e-mail: dazhukov0@gmail.com

Виноградова Екатерина Павловна, к.б.н., доцент [Ekaterina P. Vinogradova, PhD];

ORCID: http://orcid.org/0000-0003-2275-4084; eLibrary SPIN: 4899-1537; e-mail: e.vinogradova@spbu.ru

Марков Александр Георгиевич, д.б.н., профессор [Alexander G. Markov, PhD];

ORCID: http://orcid.org/0000-0002-2867-044X; eLibrary SPIN: 4985-0808; e-mail: a.markov@spbu.ru

\section{ЦИТИРОВАТЬ}

Жуков Д.А., Марков А.Г., Виноградова Е.П. Пролактолиберин увеличивает тревожность крыс // Проблемы эндокринологии. — 2021. - Т. 67. — №5. - С. 29-33. doi: https://doi.org/10.14341/probl12770

\section{TO CITE THIS ARTICLE:}

Zhukov DA, Markov AG, Vinogradova EP. Prolactin-releasing peptide increases rat anxiety. Problems of Endocrinology. 2021;67(5):29-33. doi: https://doi.org/10.14341/probl1270 